\title{
A ATUAÇÃO DO ENFERMEIRO NO TRANSPORTE AEROMÉDICO
}

Nelson Augusto MENDES ${ }^{1}$; Alexandre Vasel GARCIA 2 ; Kelli Cristina Barros MENDES ${ }^{3}$, Ana Sarah Arana GONÇALVES 4

\section{RESUMO}

O transporte aeromédico tem sido largamente utilizado na remoção de pacientes e atendimento pré-hospitalar seja por complicações de doenças crônicas, acidentes ou malestar súbito. Nesta modalidade de transporte é importante a atuação do profissional de enfermagem altamente treinado em conhecimentos de transporte aéreo e cuidados de bordo para que possa prestar os primeiros atendimentos que podem ou não contribuir para a sobrevida desses pacientes. Assim, essa revisão bibliográfica realizada por meio de artigos científicos publicados em bases de dados Google Acadêmico, Scielo, Publimed, tendo como descritores: remoção aérea, transporte aeromédico, atendimento préhospitalar, enfermagem; teve como intuito realizar um levantamento histórico sobre a atuação do enfermeiro na remoção aérea. Com resultado, é evidente a atuação do enfermeiro no transporte aeromédico, sem o qual, não haveria condições de prestar essa assistência. No entanto, ainda é tímida a iniciativa de publicações, cursos e até de profissionais especializados neste segmento de atendimento, porém, é notável o crescimento da demanda desta modalidade de transporte, com efeito o aumento das atenções de cursos, estudos e de profissionais voltados para esta habilitação.

Palavras-chave: Transporte Aeromédico, Atendimento Pré-Hospitalar, Resgate Aéreo.

\section{INTRODUÇÃO}

Dentre as atuais modalidades de transportes existentes para socorrer às vítimas no atendimento pré-hospitalar $(\mathrm{APH})$, a remoção aérea apresentou uma tendência crescente se destacando. Esse fenômeno se justifica pela rapidez deste meio de transporte, que percorre grandes distâncias em curtos intervalos de tempo, justificando-se pelas condições caóticas em que se encontra o trânsito rodoviário nas grandes cidades prejudicando o fluxo de veículos e a atuação dos serviços de saúde (DUTRA, 2004).

No Brasil, a dimensão continental explica a necessidade da existência do Serviço de Resgate Aeromédico (RAM), pois são mais de 8 milhões de km com uma população distribuída de forma heterogênea, a qual abriga a maior mata equatorial do mundo, onde o socorro médico só é possível através de barcos e helicópteros. Somado a isto, a demanda

\footnotetext{
${ }^{1}$ Pós-Graduado Enfermagem Aeroespacial - nelson@censupeg.com.br

2 Pós-Graduado Enfermagem Aeroespacial - alemaocvcwb@gmail.com

${ }^{3}$ Enfermeira Assistencial kellibarros@bol.com.br

${ }^{4}$ Pós-Graduanda em Engenharia Biomédica - ana s.a.g@hotmail.com
} 
é significativa também, pelo elevado número de acidentes rodoviários, que em geral, originam politraumas, que exigem transferências imediatas para hospitais especializados e mais bem equipados (GENTIL, 1997). O transporte aeromédico apresentou-se como um recurso ágil e eficaz no intuito de auxiliar a manter a vida e a saúde das pessoas, encurtando distâncias entre pacientes e centros de tratamento.

No Brasil, a prática da enfermagem de bordo é regida pela Lei no. 7.498/86, que regulamenta o exercício do profissional de enfermagem. E a Portaria GM 2.048 de 05/11/2002, que determina a capacitação e a temática dos profissionais do transporte aeromédico (BONUZZI et al., 2016). O Conselho Federal de Enfermagem (COFEN), pela Resolução 260/2001, passou a definir a enfermagem aeroespacial ou enfermagem de bordo como especialidade, sendo que o profissional deve ter uma boa condição física, controle emocional, criatividade e habilidades de improviso para o bom desempenho durante os procedimentos de enfermagem no transporte aéreo com asas rotativas (helicóptero).

Dessa maneira, reconhecendo o importante papel dos profissionais de enfermagem nessas modalidades de transporte, essa pesquisa tem como intuito fazer um levantamento bibliográfico sobre a atuação do enfermeiro nas remoções aéreas.

\section{METODOLOGIA}

Esta revisão sistemática, utilizou bases eletrônicas como Google Scholar, ScienceDirect, Redalyc, Scielo, OnlineLibrary e PubMed para consultas sobre o tema. levantamento bibliográfico acerca da atuação dos enfermeiros foi realizado utilizando os descritores: remoção aérea, transporte aeromédico, atendimento pré-hospitalar, enfermagem. Para tanto, os estudos foram escolhidos pelo título, posteriormente pelo resumo e, por último pelo texto completo. Os artigos selecionados foram publicados após 1986, quando a prática da enfermagem de bordo foi regida pela Lei $n$ ․ 7.498/86, sendo escritos e publicados em português ou inglês.

\section{RESULTADOS E DISCUSSÕES}

O transporte aeromédico é uma modalidade de deslocamento de paciente utilizada principalmente para assistência de doentes em estado crítico e, em muitas ocasiões, representa a única opção para que esse receba assistência em um centro especializado 
(HERNANDEZ; OLIVERA, 2007). Modernas aeronaves são empregadas para fazer a remoção em tempo hábil de pacientes quando a situação se faz crítica, conhecido como o período de ouro - tempo entre o atendimento e o transporte do paciente até o local de atendimento especializado (PHTLS³ , 2006; LEDUR, 2018). A pesquisa de Gomes et al. (2013) registrou que o uso da remoção aérea, em especial, os helicópteros, reduziram o índice de mortalidade dos feridos de 5,8\% para 2,4\% em guerras.

Essa modalidade de atendimento surgiu com as guerras, mais precisamente, com a medicina de guerra, com a assistência aos feridos em batalhas e a remoção de militares e civis feridos e doentes. Para Guimarães; Timerman e Alves (2003) o transporte aeromédico valeu-se de significativas aquisições da aviação somadas às da medicina civil nos campos de guerra tornando cada vez maior a utilização desse recurso. Acrescentam ainda, que no Brasil, as UTI's aéreas ganham cada vez mais importância, por permitir a remoção de pacientes quer de áreas remotas, ou de regiões onde os recursos são escassos para os centros de referência em saúde.

Para atender a esta demanda, a Agência Nacional de Aviação Civil (ANAC) estabelece um currículo mínimo para o treinamento da tripulação aeromédica, composta por médico e enfermeiro de bordo. A legislação vigente de 1996 estabelece como obrigatórios conhecimentos acerca de aspectos fisiológicos em voo; embarque e desembarque de pacientes; segurança no interior e em torno da aeronave; instrução aos passageiros; procedimentos apropriados de emergência em voo; de pousos de emergência e de evacuação de emergência. Estabelece ainda, um programa mínimo de formação, com curso de medicina aeroespacial aplicada ao transporte aeromédico, com a finalidade de preparar melhor a tripulação aeromédica (PASSOS, TOLEDO, DURAN, 2011).

O enfermeiro de bordo profissional que atua no resgate aeromédico, surgiu da necessidade de especializar o enfermeiro que presta assistência ao paciente aerorremovido. Atualmente, existem diferentes serviços de remoção aeromédica, no entanto, poucos ainda têm em seu quadro de tripulantes aeromédico o enfermeiro de bordo na assistência direta (THOMAZ et al., 1999). Segundo Schweitzer et al. (2011), a enfermagem de bordo é especialização recente no Brasil, com poucos cursos específicos na área, gerando uma lacuna no aprendizado dos profissionais do resgate aeromédico.

\footnotetext{
${ }^{3}$ PHTLS - Prehospital Trauma Life Support - protocolo mundialmente utilizado, especialmente em vítimas de trauma.
} 
A emergência ou atendimento pré-hospitalar tem por base atender às situações críticas de forma rápida e ordenada. No caso de ocorrências inesperadas a equipe multiprofissional precisa estar atenta a todos os fatores físicos e psíquicos que o paciente possa estar exposto (ROCHA et al., 2003). Nesse atendimento é feito o suporte básico e avançado de vida, podendo ser fixo, como as unidades de atenção à saúde, e móveis, que se dividem em atendimento terrestre, aquático e aéreo (RASIA et al., 2007; ROCHA et al., 2003). O enfermeiro é o profissional mais atuante nessas equipes, pois une os conhecimentos teóricos com a prática do cotidiano, habilidade de ensino, equilíbrio emocional e capacidade de liderança (NARDOTO et al. 2011).

Ainda, cabe ao enfermeiro fazer a avaliação inicial, realizar breve histórico e exame físico de enfermagem, verificar se há ou não indicação para remoção e elaborar o planejamento da assistência. Durante a remoção aérea avaliação deve ser realizada a monitorização constante do paciente, evolução de enfermagem, anotações dos procedimentos realizados e avaliação neurológica. $O$ enfermeiro deve ter especial cuidado na escolha dos equipamentos, pois o movimento da aeronave durante a decolagem, as vibrações durante o voo, a aterrissagem, e a alteração da altitude, podem modificar a calibração e a precisão dos equipamentos (GENTIL, 1997).

Santos et al. (2014) salientam que a atuação do enfermeiro no transporte aeromédico é de suma importância para garantir a segurança do paciente e a gestão dos riscos no ambiente assistencial. Da mesma forma, para Reis et al. (2000), o enfermeiro de bordo, deve estar ciente de suas funções e possibilidades de atuação na remoção e transporte aeromédico, desenvolvendo-se e aprimorando os seus conhecimentos para prestar uma assistência integral e eficaz.

\section{CONSIDERAÇÕES FINAIS}

O profissional de enfermagem aeromédica (ou de bordo) tem se destacado no cenário atual de assistência médica aos pacientes críticos, pela evidente importância de sua atuação no transporte aeromédico. No entanto, ainda é tímida a iniciativa de publicações científicas, cursos e até de profissionais especializados neste segmento de atendimento. Porém, com o crescimento da demanda desta modalidade de transporte, profissionais com essa habilitação estão ganhando espaço, surgindo programas de qualificação profissional, a fim de lapidar os conhecimentos dentro de tal área de atuação. 


\section{REFERÊNCIAS}

BALAGUER, D.A.; SOUZA, G.C.; PAULA, S.H.D. 0 transporte aeromédico: Um desafio para o enfermeiro frente aos riscos ocupacionais. Rio de Janeiro, 2011.

BASSI et al. Uso de suporte hemodinâmico e respiratório por meio de oxigenação extracorpórea por membrana (ECMO) venoarterial em um paciente politraumatizado. Rev Bras Ter Intensiva, 2011; 23(3:374-379). .

BAU, L.N. Voando para salvar. Rev Emergência. 2007;6(1:56-62).

BERNARDES, M.M.R.; LOPES, T. Enfermeiras do Exército Brasileiro no transporte aéreo de feridos: um desafio enfrentado na 2a. Guerra Mundial. Rev. bras. Enferm, 2007;60(1:68-72).

BONUZZI, K.L et al. Atuação do enfermeiro no atendimento pré-hospitalar aéreo a pacientes politraumatizados: revisão de literatura. Rev. Cient. Sena Aires; Jul-Dez 2016; 5(2:171-77).

COSTA, N.M.; MELLO, R.Z.R.; OLIVEIRA, T.C.M.; PARREIRAS, M.M.; SILVA, R. R.; SILVA, K.R. A Ótica empreendedora do enfermeiro: Capacitação e atuação de profissionais no transporte aeromédico. Períodico Científico Núcleo Biociências, Belo Horizonte, MG, Ago. 2013;3(5).

DUTRA, J.S. Competências: conceitos e instrumentos para gestão de pessoas na empresa moderna. São Paulo: Atlas, 2004.

GENTIL, R.C. Transporte aéreo: o diferencial na assistência de enfermagem. In: Mallagutti, W.; Caetano, K.C. Transporte de pacientes: a segurança em situações críticas. São Paulo: Yendis, 2015.

Aspectos históricos e organizacionais da remoção aeromédica: a dinâmica da assistência de enfermagem. Rev Esc Enferm USP; 1997;31(3:452-67).

GOMES, M.A. V.; ALBERTI, L.R.; FERREIRA, F.L.; GOMES, V.M. Aspectos históricos do transporte aeromédico e da medicina aeroespacial-revisão. Rev Med Minas Gerais, Minas Gerais, 2013; 23(1:116-123). 
GUIMARÃES, J.I.; TIMERMAN, S.; ALVES, P.M. Diretriz da doença cardiovascular e viagem aérea: noções de transporte aeromédico. 2003. Disponível em: http://www.publicacoes.cardiol.br/consenso/2003/site/049.pdf.>.

Acesso: Ago. 2019.

HERNÁNDEZ N.M.; OLVERA, C.E.R. Trabajo de revisión: transporte del paciente crítico. Rev Asoc Mex Med Crit Terapia Intensiva. 2007. Disponível em: <http://www.medigraphic.com/pdfs/medcri/ti-2007/ti074h.pdf>. Acesso em: Jul. 2019.

LEDUR, G.R. Transporte aeromédico brasileiro: estudo de aspectos relacionados à execução do transporte aeromédico de pacientes. TCC (Graduação). Palhoça, SC: UNISUL, 2018.

MANNARINO, L.; TIMERMAN, S. Transporte terrestre e aéreo do paciente crítico Rev Soc Cardiol, São Paulo, 1998;4(866-878).

NARDOTO, E.M.L.; DINIZ, J.M.T.; CUNHA, C.E.G. Perfil da vítima atendida pelo serviço pré-hospitalar aéreo de Pernambuco. Rev Esc Enferm USP, 2011;45(1:237-42).

ORDEM DOS MÉDICOS E SOCIEDADE PORTUGUESA DE CUIDADOS INTENSIVOS. Transportes de doentes críticos: recomendações. Centro Editor Livreiro da Ordem dos Médicos, 2008.

PASSOS, I.P.B.D.; TOLEDO, V.P.; DURAN, E.C.M. Transporte aéreo de pacientes: análise do conhecimento científico. Rev. Bras. Enferm, 2011;64(6:1127-1131).

PESSOA, LT. Medicina de aviação. Itamaracá: Cristina Publicidade Aérea; 1992.

PHTLS. National Association of Emergency Medical Technicians - NAEMT. Comitê do PHLS. PHTL Atendimento Pré-Hospitalar Traumatizado. 8. ed., São Paul: Grupo A, 2016.

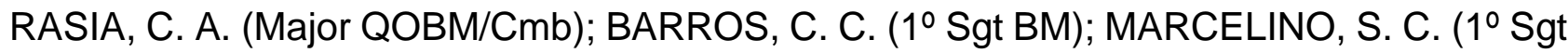
$\mathrm{BM})$; et al. Manual de atendimento pré-hospitalar - Brasília: Corpo de Bombeiros Militar do Distrito Federal, 2007.

RAVI, G.Pr.; VIJAI, W.M.; JOSHI, G.M. Monitoring during aeromedical evacuations: limitations and concerns. The Journal of Medical Research. India, Jan. 2016; 2(1:20-23). 
REIS, M.C.F.; VASCONCELLOS, D.R.; SAIKI, J. GENTIL, R.C.. [The efects of air physiology the nurses assistance to the aeromedically transported patient and the aeromedical flight crew]. Acta Paul Enferm. 2000;13(2:16-25).

ROCHA, P.K. et al. Assistência de enfermagem em serviço pré-hospitalar e remoção aeromédica. Rev. Bras. Enferm., 2003; 56(6:695-698).

SANTOS, H.G.L.; GUEDES, C.C.P.; AGUIAR, B.G.C. A segurança do paciente no transporte aeromédico: uma reflexão para a atuação do enfermeiro. Rev. Acred., 4(7:2134); 2014. Disponível em:<http://dialnet.unirioja.es/descarga/

articulo/5626590.pdf>. Acesso em: Jul. 2019.

SCHWEITZER, G. et al. Intervenções de emergência realizadas nas vítimas de trauma de um serviço aeromédico. Rev. Bras. Enferm; Jan/Fev.2017; 70(1). Disponível em: <http://www.scielo.com.br>. Acesso Jul. 2019.

SCHWEITZER, G. et al. Protocolo de cuidados de enfermagem no ambiente aeroespacial à pacientes traumatizados - cuidados durante e após o voo. Texto Contexto Enferm; Florianópolis, Jul/Set. 2011; 20(3:478-485).

SCUISSIATO, D.R.; VALOIS BOFFI, L.; ROCHA, R.R.; MONTEZELI, J.H.; BORDIN, M. T.; PERES, A.M. Compreensão de enfermeiros de bordo sobre seu papel na equipe multiprofissional de transporte aeromédico. Revista Bras. Enferm.; Brasília, Ago.2012;65(4:614-620).

THOMAZ R.R., MIRANDA M.F.B., SOUZA G.A.G., GENTIL R.C. Enfermeiro de bordo: uma profissão no ar. Acta Paul Enferm. 1999;12(1:86-96).

THOMSON, D.P. Effects of flight. Emergency medical services. New York, NY; 2015;1(368-371). 